\title{
SRXRF Experiments and Analytical Methods of Mineral Individual Fluid Inclusions
}

\author{
Wu Chunxue ${ }^{1}$, Huang Yuying ${ }^{2}$, Li Hongkui ${ }^{3}$, Chen Chuanren ${ }^{3}, \mathrm{He} \mathrm{Wei}^{2}$ and Li Kuifa ${ }^{3}$ \\ (1. College of Computer Engineering, University of Shanghai for Science and Technology, Shanghai 200093, China) \\ (2. Institute of High Energy Physics, Chinese Academy of Sciences, Beijing 100049, China) \\ (3. College of Geophysics \& Oil Resource, Yangtze University, Jingzhou, Hubei 434023, China)
}

\begin{abstract}
This paper focuses on the micro-beam and trace element non-destructive experiment and analytical method of mineral fluid inclusions by synchrotron radiation X-ray fluorescence (SRXRF) microprobe at Beijing Synchrotron Radiation Facility (BSRF). The experimental instrument, measurement process and calculating method are introduced. A set of oil- and gas-containing typical mineral fluid inclusions taken from the Tazhong and Lunnan oilfields in the Tarim Basin were analyzed non-destructively. The trace element contents in the fluid inclusions may provide guidance for oil and gas exploration and development.
\end{abstract}

Key words: Synchrotron radiation X-ray fluorescence (SRXRF), mineral fluid inclusion, experiment and analysis

\section{Introduction}

The study of fluid inclusions is currently a hot topic in the world (Vanko, et al., 1993; Li, et al., 1994; Mavrogenes, et al., 1995; Philippot, et al., 1998; Huang, et al., 2001; Wu, et al., 2002; Zhan, et al., 2002). The fluid inclusions contained in the minerals keep the original components of the fluids formed in the paleo-geologic age. Valuable physico-chemical information about the sources and properties of mineralization fluids, mineralization mechanics and the genesis of mineral deposit can be obtained from reliable

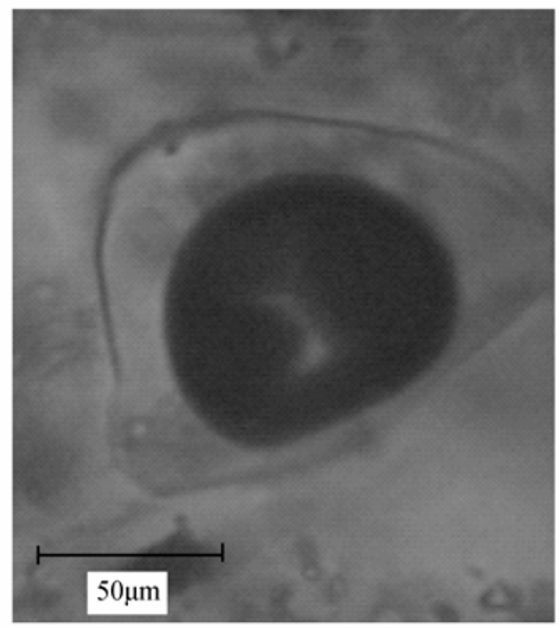

analysis of the components of fluid inclusions.

During the mineral crystallization, oil- and gas-containing mineralization fluids sometimes entered the growth defects of crystals and the inclusion that formed then is called an organic inclusion. Organic inclusions are the direct evidence of the formation, evolution, migration, and accumulation of hydrocarbons, and the studies of inclusions of such type have great development potential and application prospect. Typical oil- and gas-containing fluid inclusions taken from the Tazhong Oilfield in the Tarim Basin are shown in Fig. 1.

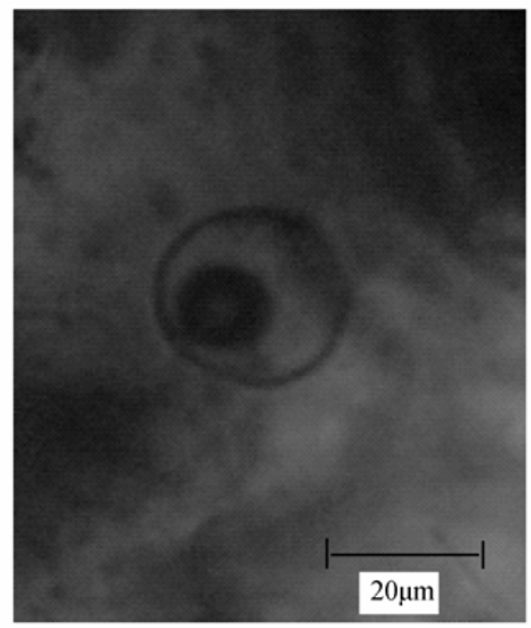

Fig. 1 Pictures of typical fluid inclusions

With the advent of high-intensity synchrotron radiation, rapid progress has been made in the nondestructive analysis of individual fluid inclusion with the X-ray fluorescence microprobe. Due to its valuable properties of high flux, high brightness, wide spectrum, continuous tunability, small divergence and good polarization performance, a synchrotron radiation light source is suitable for both trace element analysis in ppm magnitude and micro probe analysis in $\mu \mathrm{m}$ range, and causes no damages to the samples tested (Vanko, et al., 1993; Mavrogenes, et al., 1995; Philippot, et al., 1998; Zhan, et al., 2002). 
In recent years, we have undertaken and finished experimental research of nondestructive analysis of individual fluid inclusion at the Beijing Synchrotron Radiation Facility (BSRF). The final results for typical fluid inclusions indicate that this method is feasible.

\section{Experimental}

\subsection{X-ray source}

The X-ray source used in all tests is the beam line 4W1B at BSRF, which can provide polychromatic $\mathrm{X}$-rays (white light) with energy of $3-30 \mathrm{keV}$ and suitable for X-ray fluorescence analysis of most common trace elements. With $2.2 \mathrm{GeV}$ of electron energy in the storage ring, the electron beam current intensity changes from 50 to $120 \mathrm{~mA}$, with X-ray spectrum brightness of $10^{14}$ photons $/\left(\mathrm{s} \cdot \mathrm{mrad}^{2} \cdot \mathrm{mm}^{2} \cdot \mathrm{mA} \cdot 0.1 \%\right.$ band width). The X-ray intensity is high enough to excite the elements in fluid inclusions to emit detectable fluorescent signals. The horizontal and vertical angles of divergence are only $0.1 \mathrm{mrad}$ and $1.0 \mathrm{mrad}$ respectively while the experimental facility of X-ray fluorescence lies $25 \mathrm{~m}$ away from the light source, thus such a good collimated light endows SRXRF microprobe with excellent performance. Because the synchrotron X-radiation is highly polarized in the electron orbit plane of the storage ring, while X-ray fluorescence is detected perpendicular to the direction of incident ray, the signal-to-noise ratio (SNR) increases with noise from Compton scattering being greatly reduced. Hence the detection limit of elements is improved.

Therefore, the fluid inclusion to be tested in the experiment is carefully sorted, with its size over $20 \mu \mathrm{m}$. In testing, the beam of light exactly aims at the fluid inclusions. In order to lessen the absorption, the distance between the fluid inclusions and surface of the sample should be as short as possible, and then the absorption of adjustment should be done according to the depth where it is. The fluid inclusion is surrounded by the mineral, which could add to the number of elements. This could be displayed when we test it by a fluorescence device. In the experiment, the testing points relative to the fluid inclusion are chosen to be the closest 2 or 3 points under the same experiment condition in order to deduct the baseline, thereby, we can know the peak value of the numerous elements contained in the fluid inclusions. We can work out the quantity of elements with samples in NIST as a reference. With these samples, we can also figure out the minimum dection limit (MDL) of the elements and the standard deviation of the contained elements (please refer to Huang, et al., 2001). With the difference between the sorted sample and the tested one in our research, the result we figure out is only a semi-quantitative analysis which can be used to estimate the contents of elements contained in the fluid inclusion because we have not found out the fittest sample up to now.

\subsection{Experimental facilities}

The experimental station set-up mainly consists of one double knife slit, two ion chambers, a three-dimensional specimen scanning stage system, a $\mathrm{Si}$ (Li) X-ray detection system, a laser collimation system, and an optical microscope.

The X-ray beam spot is realized by using horizontal and vertical double knife slits. The spot size used in our experiments is approximately $10 \mu \mathrm{m}$ (high) $\times 10 \mu \mathrm{m}$ (wide). The ion chamber in front of the specimen is used to observe the change of X-ray intensity. The $\mathrm{Si}(\mathrm{Li})$ energy dispersive X-ray detector is made by Princeton Gamma-Tech in the USA, and its energy resolution is $134 \mathrm{eV}$ (at $5.9 \mathrm{keV}$ ), and the thickness of the thin beryllium window is $7.5 \mu \mathrm{m}$. The scanning stage made by $\mathrm{KOHOZ}$ Corporation in Japan includes three-dimensional translations with resolution of 0.25 $\mu \mathrm{m} / \mathrm{step}$. Data acquisition is performed with the Quantum MCA software from Princeton Gamma-Tech. The spectrum analysis software is AXIL made by IAEA (International Atomic Energy Agency). The optical microscope system is made by Digital Instrument Corporation in the USA. The model is OMV-PAL with 450X magnification and 10X Nikon objective (working distance $=49.5 \mathrm{~mm}$ ) and Sony high-resolution CCD color camera. The CCD in microscope system transforms the light signal into electric signal, and then the status of the sample and beam focusing will be displayed on the TV screen for the convenience of practical observation.

\subsection{Test and analysis of elemental MDL}

The minimum detection limit (MDL) with XRF at BSRF was described by $\mathrm{Wu}$, et al. (2002). MDL of elements is a function of atomic number, $Z$. This can be confirmed with a standard sample NIST612 with a thickness of $3 \mathrm{~mm}$. The standard (e.g. NIST612) and detection samples were studied under the same analytical conditions. These were $10 \mu \mathrm{m} \times 10 \mu \mathrm{m}$ microbeam, 1,000 seconds of observation time. 500 or 1,000 seconds interval time (Wu, et al., 2002; Chen, et al., 2005).

\subsection{Sample preparation and selection}

After the basic experimental conditions are available, proper preparation and selection of the sample turn out 
to be the key point of a successful experiment.

The samples used in our experiments were prepared from rock cores taken from reservoirs in different areas of oil fields, including those taken from different oil wells or from different layers and depths in one oil well. The cores were cut first and then ground into wafers. The thickness of the wafer depends on the features of rock. The wafer would be processed as thick as possible if the rock's light transmission is good (the maximum thickness of the wafer we used is $400 \mu \mathrm{m}$ ), or otherwise; but generally the thickness shall not be less than $70 \mu \mathrm{m}$. The prepared wafer were placed under microscope to check whether there was a bigger fluid inclusion or not, and under the fluorescence microscope to determine if it was an organic inclusion or a common salt water inclusion, and the size would be measured. The wafer that met experiment requirements would be taken away from the slide for rinsing and then be mounted onto the sample holder. The next step was to mark the inclusion selected for detection and then the experiment could be started.

\section{Results and discussion}

To check the feasibility of nondestructive analysis of individual fluid inclusion with SRXRF, some researches have been done (Li, et al., 1994; 1995; Huang, et al., 2001; Wu, et al., 2002). The fluid inclusions tested were $75 \mu \mathrm{m} \times 50 \mu \mathrm{m}$, big enough, set test point every $10 \mu \mathrm{m}$ interval, with individual SRXRF microbeam. The fluorescence counts that represent the components held in these heterogeneous bodies are acquired and the element distribution per point is given after deducting the background.

The analysis with SRXRF microbeam on a batch of fluid inclusions measuring over $10 \mu \mathrm{m} \times 10 \mu \mathrm{m}$ with complex basis and surrounded by quartz minerals and other semi-transparent material was done. After times of detections and analyses with background deducted, the results of 16 elements' contents represented by fluorescence counts were obtained.

The results from the above researches indicate that the qualitative analysis on individual fluid inclusion with the detection method and technology designed by authors is feasible. On this basis, a semi-quantitative or quantitative component analysis was carried out on some typical individual organic fluid inclusions.

The thing showing like a ball is actually a bubble in an inclusion measuring $20 \mu \mathrm{m} \times 40 \mu \mathrm{m}$ approximately. The X-ray microbeam applied in experiment was of $10 \mu \mathrm{m} \times 10 \mu \mathrm{m}$ size; the size of most inclusions was $15-20$ $\mu \mathrm{m}$, some over $25 \mu \mathrm{m}$. The standard sample was the NIST612 as mentioned above, which was a glass wafer containing 26 elements whose concentrations were known. The thickness of the sample wafer that held organic inclusion inside was approximately $0.1 \mathrm{~mm}$, and the background differed greatly from that of selected standard sample. In this method, the absorption correction of fluorescence radiation, which was treated as a function of overlying thickness over the inclusion, was also taken into account. The analysis results of 16 inorganic elements of $\mathrm{K}, \mathrm{Ti}, \mathrm{V}, \mathrm{Cr}, \mathrm{Mn}, \mathrm{Fe}, \mathrm{Co}, \mathrm{Ni}, \mathrm{Cu}$, $\mathrm{Zn}, \mathrm{Rb}, \mathrm{Sr}, \mathrm{Y}, \mathrm{Zr}, \mathrm{Ba}$, and $\mathrm{Pb}$ were obtained with this method. The representative detection results are listed in Table 1.

What can be learned from non-destructive analysis on elements contained in individual fluid inclusions with synchrotron radiation X-ray fluorescence microprobe are the distribution characteristics of trace elements of transition subgroup. While applying this method, the individual fluid inclusion can be observed and evaluated to identify its type and phase composition with microscope in advance, and an inclusion sample of either same or different generation can be selected according to relevant geologic information. The generality and difference of data obtained from this method are clear at a glance, because the geologic information represented by the data is definite. And one sample can be used in many analyses, for there are no damages caused on inclusion during test.

Table 1 lists the analysis results of a group of representative oil- and gas-containing fluid inclusions from exploration areas in Tazhong and Lunnan oilfields in China. The distribution characteristics of metal trace elements show definite geologic significance.

Table 1 Detection results of 8 fluid inclusi(pgig)

\begin{tabular}{ccccccccccccccccc}
\hline No. Formation & $\mathrm{K}$ & $\mathrm{Ca}$ & $\mathrm{Ti}$ & $\mathrm{V}$ & $\mathrm{Cr}$ & $\mathrm{Mn}$ & $\mathrm{Fe}$ & $\mathrm{Co}$ & $\mathrm{Ni}$ & $\mathrm{Cu}$ & $\mathrm{Zn}$ & $\mathrm{Rb}$ & $\mathrm{Sr}$ & $\mathrm{Au}$ & $\mathrm{Pb}$ \\
\hline 1 & $\mathrm{~J} 1-17$ & 143.1 & 1000 & 5266 & 40.6 & 12.5 & 7.6 & 343.4 & 0.5 & 0.0 & 1.2 & 4.1 & 5.2 & 3.9 & 0.3 & 6.2 \\
2 & $\mathrm{~J} 1-30$ & 21.8 & 0 & 105.4 & 1.4 & 16.5 & 1.2 & 250.3 & 2.1 & 2.1 & 0.1 & 1.8 & 0.0 & 0.0 & 0.3 & 1.4 \\
3 & $\mathrm{~J} 1-59$ & 65.8 & 0 & 366.1 & 5.4 & 126.7 & 66.8 & 407.3 & 2.3 & 1.6 & 0.0 & 6.3 & 0.0 & 0.0 & 0.4 & 3.2 \\
4 & $\mathrm{~J} 2-9$ & 10.3 & 0 & 114.1 & 4.5 & 5.9 & 44.7 & 1417 & 17.3 & 0.7 & 0.9 & 1.2 & 363.1 & 0.0 & 1.4 & 5.9 \\
5 & $\mathrm{~J} 2-5$ & 16.2 & 0 & 36.9 & 3.7 & 18.8 & 5.4 & 882.3 & 4.1 & 0.0 & 7.0 & 11.2 & 91.3 & 0.0 & 0.2 & 0.0 \\
6 & $48-14(1)$ & 207.4 & 13000 & 35.6 & 0.0 & 360.2 & 8.3 & 42.0 & 5.4 & 0.9 & 0.4 & 2.3 & 4.1 & 4.4 & 0.0 & 1.9 \\
\hline
\end{tabular}


Continued

\begin{tabular}{|c|c|c|c|c|c|c|c|c|c|c|c|c|c|c|c|c|}
\hline No. & Form & $\mathrm{K}$ & $\mathrm{Ca}$ & $\mathrm{Ti}$ & $\mathrm{V}$ & $\mathrm{Cr}$ & $\mathrm{Mn}$ & $\mathrm{Fe}$ & $\mathrm{Co}$ & $\mathrm{Ni}$ & $\mathrm{Cu}$ & $\mathrm{Zn}$ & $\mathrm{Rb}$ & $\mathrm{Sr}$ & $\mathrm{Au}$ & $\mathrm{Pb}$ \\
\hline 7 & $103-12$ & 1 & 0 & 24.2 & 2. & 3 & 22.3 & 18.7 & 2.5 & 1 & 0.0 & 16.1 & 2.0 & 0.0 & 1.3 & 0.0 \\
\hline 8 & 103 & 56.2 & 453000 & .0 & 0 & & 5 . & & 0.5 & 5.0 & .0 & 2.6 & .1 & 1.4 & 0.0 & 3.5 \\
\hline 9 & $103-16$ & 33.9 & 0 & 101.5 & 15.0 & 588.5 & 41.6 & 432.4 & 0.0 & 21.4 & 59.1 & 80.2 & 0.0 & 3.5 & 1.7 & 404.4 \\
\hline 10 & $103-16(2)$ & 80.2 & 1000 & 34.5 & 21.0 & & 5.7 & 150.4 & 25.6 & 29.2 & 28.5 & 66.1 & 0.0 & 14.1 & 0.0 & 171.0 \\
\hline 11 & $103-17$ & 3824.5 & 0 & 30.0 & 2.2 & 51.3 & 0. & 204.1 & 42.9 & 4.8 & 6.6 & 4.9 & . & 0.0 & 0.6 & 11.0 \\
\hline 12 & $103-18(1)$ & & 0 & .8 & 2.5 & 50.3 & 0 . & 3.5 & 11.0 & 1.7 & 6 & 29 & 0.0 & 30.1 & 0.0 & 28.2 \\
\hline 13 & 100 & 6 & 0 & & 3.8 & & & & 38.9 & & & & & 0.0 & 0.0 & 0.0 \\
\hline 14 & & & - & & 0.0 & 56 & 0.0 & 430.8 & 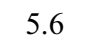 & & & . & & 3.4 & 0.0 & 36.4 \\
\hline 15 & TZ1 & 1 & 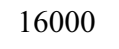 & 5 & 0.0 & & & & & & & & & 6 & 0 & 30.7 \\
\hline 16 & $103-2$ & & 1 & 3.0 & 2. & 41 & 0 . & 19.7 & 7 & 17 & 27.0 & 47.3 & & 39.2 & 8.5 & 7.9 \\
\hline 17 & $103-22(2)$ & 16.0 & 0 & 151.4 & 0.4 & 127.4 & 0.0 & 63.4 & 1.2 & 0. & 0.0 & 0.0 & 19.5 & 59.7 & 0.0 & 43.6 \\
\hline 18 & $103-22(3)$ & 26.4 & 1000 & 2074 & 71.5 & 32.2 & 0.0 & 21.2 & 6.2 & 12. & $0 .($ & 31.8 & 0.0 & 27.7 & 6.2 & 114.8 \\
\hline 19 & $103-$ & 22.4 & 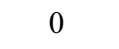 & 82.2 & 1.8 & 24.2 & 17.2 & 99.4 & 102.5 & 16. & 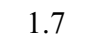 & 36.9 & 0.0 & 239.1 & 0.0 & 0.0 \\
\hline 20 & $103-2$ & 132.5 & 2000 & 1266 & 50.4 & 62.8 & 0 & 30.3 & & 13.9 & U & 3. & 0.0 & 33.1 & 1.6 & 0.0 \\
\hline 21 & $105-$ & & & & & & & & & & & & & & & 11.4 \\
\hline 22 & $103-25(2)$ & 443.2 & 11000 & 550.2 & 9.9 & & & 111.7 & & & 0.0 & 27.8 & 4.6 & 0.0 & 0.0 & 0.0 \\
\hline 23 & & & & 209.2 & 2.0 & & & & 0.9 & 0 . & 6.0 & & 9.0 & 0.0 & 2.0 & 10.9 \\
\hline 24 & $103-5$ & 167.0 & 172000 & & 0.0 & 186.1 & 350.8 & 257.0 & 3.4 & 12 & 2.7 & 1 & 0 & 3.7 & 0.0 & 0.0 \\
\hline 25 & $103-50(2)$ & 14.2 & 1000 & 103.8 & 10.8 & 29.4 & 86.0 & 67.6 & 53.5 & 24.2 & 18.5 & 21.7 & 0.0 & 0.0 & 0.0 & 13.7 \\
\hline 26 & $103-5$ & 212.1 & 1000 & 51.9 & 0.7 & 79.9 & 17.8 & 20.3 & 21.2 & 7.2 & 0.0 & 113.9 & 21.1 & 0.0 & 14.7 & 32.8 \\
\hline 27 & $103-50(4)$ & 34.4 & 0 & 114.2 & 8.9 & 85.3 & 0.0 & 74.3 & 14.0 & 36.9 & 105.3 & 83.8 & 0 & 0.0 & 0.0 & 0.0 \\
\hline 28 & $103-62$ & 150.7 & 1000 & 108.0 & 4.1 & 161.1 & 5.1 & 149.5 & 1.6 & 3.8 & 5.0 & 10.7 & 80.3 & 11.7 & 0.0 & 84.5 \\
\hline 29 & $103-7(1)$ & & 2000 & 70.5 & 5.0 & 97.2 & 1.3 & 79.7 & 0.0 & 2. & 2.6 & 2.6 & 0.0 & 7.3 & 0.0 & 1.6 \\
\hline 30 & $103-7(2)$ & 239.4 & 1000 & 838.4 & 32.0 & 28.0 & 0.0 & 464.3 & 3.7 & 0.9 & 0.0 & 2.8 & 17.1 & 263.4 & 0.0 & 0.0 \\
\hline
\end{tabular}

Notes: Samples No.1-No.6 were from Lunnan Oilfield and No.7-No.30 from Tazhong Oilfield. L(n) means that L is label number of samples and (n) is different inclusions in the $\mathrm{L}$ sample

\section{Conclusions}

Non-destructive analysis of individual fluid inclusions with a synchrotron radiation X-ray fluorescence micro probe has been developed preliminarily under the conditions available at BSRF fluorescence experimental station. The detection limit with relative concentration of $\mu \mathrm{g} / \mathrm{g}$ magnitude is achieved when the size of microbeam is modulated down to the level of $10 \mu \mathrm{m} \times 10 \mu \mathrm{m}$. The analysis results of the trace elements held in fluid inclusions are given. Due to the specificity and uniqueness of the geologic information represented by the selected inclusions, and better reliability of the data obtained from the bigger inclusion close to the surface of wafer, the application prospect of this method is quite good when it is used in evaluation and exploration of oil gas reservoir. From the reference results, it can be seen that the researches and analyses on fluid inclusions (mainly the inclusions that contain gas and oil components) will provide a new method for petroleum exploration and development and have good application prospect. With further study, the microelement content in the fluid inclusion will provide guidance for oil and gas exploration and development, and provide valuable information for other researches, such as microelement distribution, ratio of special elements to element varieties.

In the experimental station, many instruments will be upgraded, so the experimental environment and data precision would be greatly improved. The special non-standard sample analysis software for the oil- and gas-containing fluid inclusions is in progress and will obtain some better results in the near future.

\section{Acknowledgements}

This paper was supported by the Key Program of BSRF, the National Natural Science Foundation of China (No. 49872051 and No. 40472080) and Hubei Provincial Department of Education Innovation Foundation (No. 2004J001).

\section{References}

Chen C. R., Huang Y. Y., Li J. G., He W., Wei A. H., Wu Q. H., Wu C. X. and Li F. K. (2005) Study of the relationship between the trace element of oil-gas inclusion and oil-gas movement. High Energy Physics and Nuclear Physics, 
29(Supp.), 51-55 (in Chinese)

Huang Y. Y., Li K. F., He W., et al. (2001) Single fluid inclusion study by SRXRF microprobe. Nuclear Instruments and Methods in Physics Research A, 467-468, 1315-1317

Li K. F., Fang X. L., Liu C. Q., Niu Y. H., Zhang J. S. and Xiao Y. A. (1994) Detecting trace elements geological samples with synchrotron radiation X-ray fluorescence analysis. Journal of Jianghan Petroleum Institute, 16(1), 23-28 (in Chinese)

Li K. F., Fang X. L., Niu Y. H., and Wu Y. R. (1995) The application of synchrotron radiation $\mathrm{X}$-ray fluorescence analysis in petroleum exploration. Physics, 24(12), 755-758 (in Chinese)

Mavrogenes J. A., Bodnar R. J., Anderson A. J., et al. (1995) Assessment of the uncertainties and limitations of quantitative elemental analysis of individual fluid inclusions using synchrotron radiation X-ray fluorescence (SXRF). Geochimica et Cosmochimica Acta, 59(19), 3987-3995

Philippot P., Menez B., Chevallier P., Gibert F., Legrand F., and Populus P. (1998) Absorption correction procedures for quantitative analysis of fluid inclusions using synchrotron radiation X-ray fluorescence. Chem. Geol., 144, 121-136

Vanko D. A., Sutton S. R., Rivers M. L., et al. (1993) Major-element ratios in synthetic fluid inclusions by synchrotron X-ray fluorescence microprobe. Chem. Geol., $109,125-134$
Wu, C. X. , Huang Y. Y., Yang C., Li J., He W., Yu Z. W., Lin K. X. and Li K. F. (2002) Nondestructive analysis of individual fluid inclusion based on SRXRF and its application in oil geology. Nuclear Techniques, 125(10), 793-798 (in Chinese)

Zhan X. C., Ma G. Z. An Q. X., Huang Y. Y., Wu Y. R. and Li G. C. (2002) Discussion on some problems related to fluid inclusion analysis by SXRF. Spectroscopy and Spectral Analysis, 20(3), 395-398 (in Chinese)

\section{About the first author}

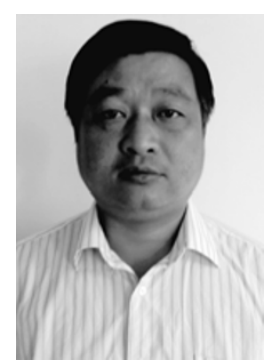

Wu Chunxue was born in 1964 and received his $\mathrm{PhD}$ degree from China University for Mining and Technology (Beijing) in 2006. Mr. $\mathrm{Wu}$ is now working as a professor with University of Shanghai for Science and Technology (Shanghai, China). His specialty is applications of computer in oil fields with special interests in test and analysis methods of single fluid inclusions. E-mail: tyfond@126.com 